\title{
Role of Social Networks in the Help-seeking Experiences among Chinese Suffering from Severe Mental Illness in England: a qualitative study
}

Echo, Y. W., Yeung, Senior Lecturer of Centre for Social Work, Faculty of Health and Applied Social Sciences, Liverpool John Moores University, UK and PhD student in the Department of Social Work and Social Administration, the University of Hong Kong

Fiona Irvine, Professor of Nursing and Head of Research and Scholarship, Faculty of Health, Staffordshire University, UK

Siu-Man, Ng, Assistant Professor of Department of Social Work and Social Administration and Associate Director of Centre on Behavioral Health, The University of Hong Kong

Sandra, K. M., Tsang , Associate Professor and Head of Department of Social Work and Social Administration, The University of Hong Kong

Corresponding author: Echo, Yuet-Wah, Yeung, Centre of Social Work, Faculty of Health and Applied Social Sciences, Liverpool John Moores University, 79, Tithebarn Street, Liverpool, L2 2ER, UK.

Email: y.yeung@ljmu.ac.uk 


\title{
Role of Social Networks in the Help-seeking Experiences among Chinese Suffering from Severe Mental Illness in England: a qualitative study
}

\begin{abstract}
The onset of mental illness can have a significant impact on individuals' lives and on the people who they come into contact with in their social networks. This paper presents the findings of the exploratory stage of a larger study which aims to examine the role of social networks in the help-seeking process of Chinese people suffering from severe mental illness in England. The study used a qualitative phenomenological approach in which in-depth interviews were conducted with three Chinese people suffering from severe mental illness and four network ties who were involved in the help-seeking process. The results of the study showed that family may not be involved in every stage of help-seeking. The size of social networks of Chinese people suffering from mental illness became bigger and the composition of social networks became more diverse after their first contact with mental health services. The implications of the study encourage social workers and mental health professionals to explore resources in the wider social networks to ensure that Chinese people suffering from mental illness receive adequate support to meet their mental health needs.
\end{abstract}

Keywords: Chinese, mental illness, help-seeking, social networks 


\section{Role of Social Networks in the Help-seeking Experiences among Chinese Suffering from Severe Mental Illness in England: a qualitative study}

\section{Introduction}

The Chinese community has a long history of more than 150 years in Britain. They first arrived in the country as seamen and hence their early settlements tended to cluster near major seaports such as London, Liverpool and Bristol. The 2001 census found that there were 247,403 Chinese living in the UK, which made up $0.4 \%$ of the total population (Office for National Statistics, 2002). Only 29\% of the Chinese population was born in the UK and the rest were immigrants mainly from Hong Kong, China, Malaysia, Singapore and Vietnam. As many British Chinese (50\%) work in the catering related business and the nature of this industry discourages concentration of the population, the Chinese population tends to scatter across the country (Chan et al., 2007).

Current literature suggests that minority ethnic groups are generally over-represented in mental health systems in England (Care Quality Commission, 2010). However, according to the Information Centre (2006), the Chinese are less likely to report psychological distress and to seek help from primary health care for mental health problems. The Care Quality Commission (2010) found that there were only 82 Chinese inpatients in mental health units in England and Wales on the day that they completed their census. Overall, 22\% of all patients were from black and minority ethnic groups. The admission rates among the Chinese group ( $0.3 \%$ of all patients) were lower than average but compulsory admissions for the Chinese (67\%) were higher than average (47\%). The Chinese were more likely to be admitted through A\&E than the national average. 
The high detention rates and higher referral rates from A\&E of the Chinese group implies that many Chinese come into contact with mental health services in crisis situations which often results in compulsory admissions. The low rate of use of mental health services at community level and high level of severity of mental illness for those who subsequently contact specialist mental health services suggests that there is an under-utilization of mental health services. The problem of under-utilization was also observed among Chinese Americans (Kung, 2003) and Chinese Australians (Klimidis et al., 2007).

The Chinese hold diverse views towards mental illness. Philip et al. 's (2000) study found that Chinese people living in rural areas in China tended to adopt supernatural and moralistic perspectives. The supernatural view recognizes that mental illness is a result of an invasion of evil spirits of one's body. Mental illness is seen as a form of punishment because of the 'wrong-doing' of an individual or one's ancestor. Chinese people holding these views will seek help from folk healers (Chong et al. 2005; Gill et al., 2005). Because of the association of 'immoral conduct' with people suffering from mental illness and their family, the moralistic perspective results in a strong stigma being attached to mental illness. Li and Logan (1999) found that stigma associated with mental illness was perceived by Chinese community workers as a major barrier to seeking professional help in England. These findings provide some of the explanations for underutilization of mental health services.

People suffering from severe mental illness (SMI) such as schizophrenia and affective bipolar disorder often display socially disruptive behaviours which will make them more noticeable to those people they come across in their social networks. Also, as some of the major symptoms of SMI can significantly alter one's cognitive ability, the sufferers may not 
have the insight to detect mental illness symptoms (Craddock et al., 2005); they may not recognize that they need help or may even refuse to get help. Therefore, social networks play a major role in directing the help-seeking trajectory.

Many researchers have conducted empirical studies that examined the relationship between social networks and the help-seeking behaviours of those affected by SMI. For example, Albert and colleagues (1998) completed a literature review of 24 network studies and found that 15 of the studies revealed that small social networks were strongly related to more use of inpatient mental health services. Apart from the size, the composition of social networks can also impact on help-seeking. In a cross-cultural study involving Chinese Canadians, Ryder et al. (2000) found that the presence of family was more likely to result in delayed instead of early contact with mental health services. The results of these studies give some insight into the significance of the structure of social networks on the help-seeking journeys of people suffering from SMI.

Network structure not only affects the direction and duration of help-seeking of those affected by mental illness, but in turn, mental illness can also change the structure of social networks. People with SMI tend to have small social networks; a network size of less than four is considered to be small (Pescosolido and Wright, 2004). According to Holmes-Eber and Riger (1990), while repeated admissions to psychiatric hospital has little effect on network size; it does effect network composition since fewer relatives and friends feature in social networks and more people meet in the mental health context. Holmes-Eber and Riger (1990) explained their findings by suggesting that the negative attitudes and reactions of those who were close 
to the sufferers of SMI could lead to a network crisis and therefore it was more likely for close relations to leave the networks.

To date, there is limited research evidence to examine the relationship between social networks and help-seeking of Chinese people affected by SMI in different Chinese societies. Lin and Lin (1981) found that only families and close family friends were involved in the early stages of help-seeking amongst Chinese Canadians suffering from SMI. As repeated relapses and hospitalizations brought shame to the family, the family would gradually leave and abandon the mentally ill relative. As Lin and Lin's study was carried out about 30 years ago, the findings may not be relevant to the current position. Wong's (2007) study found that both informal and formal networks supplied access information and advice for families with young relatives suffering from early psychosis in Hong Kong, which promoted early contact with specialist mental health services. However, as the study population concerns Hong Kong people who live in a Chinese society, their experiences may not be relevant to overseas Chinese who belong to a minority ethnic community in the UK.

Despite the long history of the Chinese community in the UK, little is known about their use of mental health services. There is evidence to suggest that British Chinese still assume that it is the family's responsibility to take care of the old and sick in the family (Chiu and $\mathrm{Yu}, 2001$ ). Chan et al.'s (2007) study attempted to unravel how social networks of British Chinese impact on general help-seeking behaviours. However, the role of family and the wider social networks in the help-seeking process of people suffering from SMI remains an unexplored terrain among British Chinese and the absence of empirical work leads to the development of this study. This paper reports on the findings of the exploratory phase of the 
study. It aims to explore the role of social networks in the help-seeking experiences of Chinese people suffering from SMI in England; and to examine how mental illness affects the structure and function of their social networks and how these changes alter subsequent helpseeking behaviours.

\section{Method}

\section{Design}

This qualitative study adopted a phenomenological approach to conduct in-depth interviews to capture the complex help-seeking experiences of Chinese people suffering from SMI in England. Central to phenomenology is its emphasis on conscious experiences and the subjective experience of the lived world (Husserl, 1983). This study drew on the strength of two main streams of phenomenological approaches; Husserl's descriptive phenomenology and Heidegger's interpretive / hermeneutic phenomenology (Dowling, 2007). Descriptive phenomenology concerns the descriptions of the original and the natural world of everyday living that is free from presumptions. In order to preserve the essences and originalities, researchers are required to keep their personal assumptions at bay; this can be achieved by bracketing one's prior knowledge and focussing on the essence of the phenomenon under study (Moustakas, 1994).

Interpretative phenomenologists believe that when undertaking an enquiry, seekers of knowledge are often guided by what is sought (Heidegger, 1962). Inquirers inevitably bring certain prior knowledge and experiences to help them understand and explain the phenomenon and it is therefore impossible for them to withhold their presuppositions. Understanding is like 
a 'hermeneutic circle', a reciprocal activity and interpretation is essential during the process of inquiry (Polkinghorne, 1983). We argue that although prior knowledge could contaminate the research process, foreknowledge should not be totally put aside. This study followed the phenomenological research methods and procedures proposed by Moustakas (1994) which embraced both descriptive and interpretive approaches. The early stages of data collection and analysis were guided by descriptive phenomenology and the later stages followed an interpretative phenomenological approach.

\section{Participants}

Convenience sampling was used to recruit three Chinese people, who were suffering from SMI, aged over 18 and were willing to give informed consent. Four network ties who were involved during help-seeking were also interviewed; they included spouses (one husband and one wife), a family friend and a Chinese community worker. The study obtained approval from the relevant research ethics committees in Hong Kong and the UK. Issues of confidentiality were assured. Bilingual counselling services were available should participants wish to seek counselling support.

\section{Data collection}

Recruitment information was sent to two Chinese community projects in England that provided support services for Chinese people suffering from SMI. Project managers explained the purpose and voluntary nature of the study to potential research participants and then invited them to take part. All the recruitment leaflets and consent forms were produced in both Chinese and English. Unstructured face-to-face interviews were conducted with most of the 
participants and a telephone interview was carried out with a Chinese community worker. All the interviews were conducted by the first author (EY), a bilingual Cantonese and English speaker. Participants were invited to use their preferred language so that they could fully express the essence of their experiences. All interviews were conducted in Cantonese and were audio taped. Field notes were taken to record contextual information that could not be captured by the recorder.

As the primary researcher was a social worker working with Chinese people affected by SMI in England for many years and has some prior knowledge of the research question, the phenomenological 'bracketing' approach advanced by Husserl was used at the early stages of data collection to minimize the impact of personal bias. The 'bracketing' approach demanded the researcher to withhold any personal presuppositions so that the description could be the true reflection of participants' subjective experiences (Moustakas, 1994; Dowling, 2007). This approach also provided space for participants to fully articulate the meaning of their helpseeking experiences. To achieve this, open-ended questions such as "how would you describe the help-seeking experience?' and 'what does mental illness mean to you?' were asked.

In the later stages of data collection, prior knowledge was incorporated into the interpretation of participants' help-seeking experiences and was used to reframe the questions in follow-up interviews to clarify, validate or enhance our understanding of the meanings of their experiences. Being reflective was another means of preserving the essence of participants' experiences. The researcher kept a reflexive diary to review and examine how presuppositions could impact on the research process (Wall et al., 2004). Some of the presumptions included 'language difference as a barrier' and 'stigma attached to mental illness 
prevents early intervention'. They were recorded in the diary so that the researcher could reflect on how they could have hindered or facilitated participants' expressions of their lived experiences.

\section{Data analysis}

All the recorded interviews were transcribed in Chinese by EY. As meaning can be lost and misinterpreted in translation (Irvine et al., 2008), analysis of transcripts and coding were undertaken in Chinese. This allowed the researcher to maintain the core meaning of the raw data which is consistent with the phenomenological approach. Only identified key themes and verbatim quotes presented in this paper were translated into English. Pseudonyms were assigned to participants to protect their identity.

To avoid interferences from any foreknowledge of the research questions, no pre-set coding system was used. The process of data analysis began with horizonalization; giving every horizon or statement relevant to the research question under study an equal value (Moustakas, 1994, p.118) so that original meanings of the experience were not removed. Meaning units relevant to help-seeking were identified and the textual description of each help-seeking journey was developed. For each help-seeking journey, critical incidences that activated intervention from individual's social networks were identified. The next step was to apply prior knowledge to help interpret and understand participants' experiences so that the phenomenon of the help-seeking experiences across cases could be synthesized. A sample of the transcripts was examined independently by another experienced researcher. The coding scheme was developed through re-examinations between the researchers. Some of the identified common themes included 'medical pluralism' and 'abandonment'. Field notes and 
the reflective diary were also used during data analysis. Extracts of the reflective diary (in italics) are used in this paper to illustrate how the findings helped to confirm and challenge some of the preconceptions and how the prior knowledge could clarify and explain people's help-seeking experiences.

\section{Findings and Discussions}

All the research participants were immigrants to the UK. Other information about the participants and their network ties is given in Table 1.

\begin{tabular}{|c|c|c|c|}
\hline $\begin{array}{l}\text { Person suffering from } \\
\text { SMI (gender/ age at } \\
\text { the time of interview) }\end{array}$ & Mei (F / 62) & Keung (M / 44) & Wah (M / 39) \\
\hline Educational level & Primary school & Primary school & $\begin{array}{l}\text { University } \\
\text { graduate }\end{array}$ \\
\hline $\begin{array}{l}\text { English language } \\
\text { skills }\end{array}$ & Limited & Limited & Fluent \\
\hline Place of birth & Hong Kong & Vietnam & Hong Kong \\
\hline $\begin{array}{l}\text { Employment history } \\
\text { (before / after contact } \\
\text { with mental health } \\
\text { services) }\end{array}$ & $\begin{array}{l}\text { Catering industry / } \\
\text { voluntary work }\end{array}$ & $\begin{array}{l}\text { Catering industry } \\
\text { / unemployed }\end{array}$ & $\begin{array}{l}\text { Short-term } \\
\text { employment in } \\
\text { commercial } \\
\text { sector/ voluntary } \\
\text { work }\end{array}$ \\
\hline $\begin{array}{l}\text { Length of time } \\
\text { between recognition of } \\
\text { mental illness and } \\
\text { first contact with } \\
\text { mental health services } \\
\text { in Britain } \\
\end{array}$ & 24 months & within a week & 18 months \\
\hline $\begin{array}{l}\text { Person that prompted } \\
\text { first contact with } \\
\text { mental health services }\end{array}$ & Husband & Parents & Neighbour \\
\hline $\begin{array}{l}\text { Network ties } \\
\text { interviewed (age / } \\
\text { ethnic origin/ English } \\
\text { language skills) }\end{array}$ & $\begin{array}{l}\text { Husband (70/ } \\
\text { Chinese /limited } \\
\text { English) and family } \\
\text { friend (65/ Chinese/ } \\
\text { limited English) }\end{array}$ & $\begin{array}{l}\text { Wife (43/ } \\
\text { Chinese/ limited } \\
\text { English) }\end{array}$ & $\begin{array}{l}\text { Chinese } \\
\text { community } \\
\text { worker (51/ } \\
\text { Chinese/ fluent } \\
\text { English) }\end{array}$ \\
\hline
\end{tabular}




\begin{tabular}{|l|l|l|l|}
\hline $\begin{array}{l}\text { Living environment } \\
\text { (before / after first } \\
\text { contact with mental } \\
\text { health services }\end{array}$ & Semi-rural / urban & Semi-rural /urban & Urban / urban \\
\hline
\end{tabular}

Table 1: Participants' characteristics

\section{Help-seeking experiences}

Our findings did not demonstrate a unified help-seeking pattern. As shown in Figure 1, Mei and Wah experienced a long delay before their first contact with mental health services but Keung received support from mental health professionals within a week. The distance they travelled before their first contact of mental health services in the UK seemed to affect the direction of their help-seeking journey. A delay in getting professional support for Mei and Wah led to their long stays (nearly 12 months) in hospital for treatment. Keung received treatment in the community because of prompt actions taken by his parents.

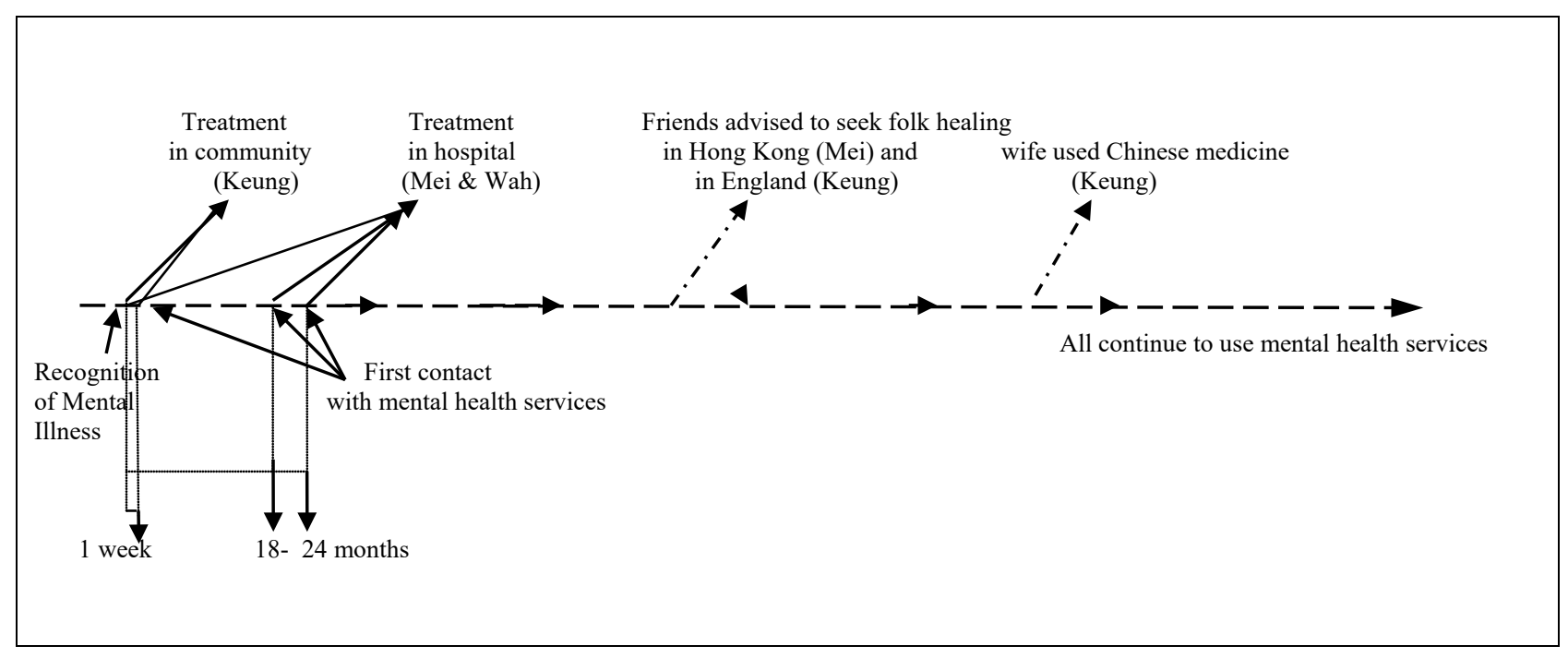

Figure 1: Duration and direction of help-seeking experiences

Our study finds that personal factor such as proficiency in English is an important variable that can impact on help-seeking. The ability to speak English has been found to be 
the strongest predictor of use of primary health care services among British Chinese (Aspinall, 2007). Language differences posed a difficulty for Mei and her husband, who struggled to communicate with medical professionals and this resulted in a significant delay in getting specialist support. Yet, although Keung and his parents could not speak fluent English, their early contact with GPs led to immediate referral to specialist mental health services. In Wah's case, despite his proficiency in English, he also experienced a delay in obtaining specialist support. It is fair to say that solely using individuals' attributes is limited in explaining complex social behaviours (Polkinghorne, 1983; Knoke and Yang, 2008; Kirke, 2009) and differing help-seeking experience in this study. Our study found that when people first developed symptoms of SMI, it was difficult for them to get professional support without the help from their social connections. It also revealed that those who were available to provide support and advice and the actions that these people took could change the distance and direction of help-seeking. To this end, social network analysis is used to explain how structure and function of one's social networks impact on help-seeking experiences (Knoke and Yang, 2008).

\section{Structure of social networks and its relationship with help-seeking}

\section{Size and composition}

This study showed that Chinese people suffering from SMI had a small social network before they first contacted mental health services; the network size ranged from 2-4. The network composition was confined to their immediate families and people working in the Chinese catering business. When Mei's mental health deteriorated, her husband attempted to seek help from his relatives but he found that: 
'There was no one to help; they (relatives) were busy with their business (take-away).' When Keung first developed symptoms of mental illness, he was working in another city. He said:

'My colleagues in the take-away noticed I was different, they contacted my parents immediately.'

Our study found that apart from immediate family, other people such as Keung's colleagues and GP were also involved at the early stage of help-seeking. In relation to Wah, his family was not involved in help-seeking at any stage. This was dissimilar to Lin and Lin's (1981) work with Chinese Canadians in Vancouver, which found that the initial stages of help seeking were marked by exclusively intrafamilial coping. The 'closed enmeshed system', a term used by the family therapists (Olson and Grorall, 2003), best described the help-seeking experience of Canadian Chinese; the family guarded the boundary by keeping outsiders away and individuals were granted limited autonomy to make any health care choice. However, our findings dispute this view. The free medical care provided by the NHS in the UK and Wah's proficiency in English, which enabled him to live more independently and with less reliance on his family, could be a possible reason for the difference in findings.

Previous studies involving Chinese showed that because of the stigma of mental illness, families of people suffering from SMI were inclined to keep the mental illness a secret (Lin and Lin, 1981; Lee et al., 2005). A study on Hong Kong Chinese showed that $60 \%$ of the participants attending psychiatric outpatient clinic revealed that their family wanted to conceal their mental illness to avoid stigmatizing comments (Lee et al., 2005). Hence, it was more likely that family involvement in help-seeking among Chinese people would cause delay in 
getting professional help (Ryder et al., 2000). The divergent help-seeking experiences in our study challenge such conclusions. Family involvement in Keung's situation led to immediate, instead of delayed contact with mental health services.

I was shocked by Keung's story; it challenged my understanding of the Chinese community. My previous work experience with the community informed me that because of stigma of mental illness, families often delayed seeking help outside family (extract from reflexive diary).

Hortwitz's (1978) seminal study offers a plausible account to explain such a finding; the involvement of friends encouraged early contact with mental health services because friends would not be affected by the stigma associated with mental illness and they might not want the burden of looking out for people with mental health problems. Keung's family was alerted by his colleagues, who were able to detect signs of mental illness. The colleagues also urged his parents to seek professional support immediately. From the family's perspective, since the 'family disgrace' had been exposed, there was no need for Keung's parents to hide his mental health problem and it seemed logical for them to seek advice from the professionals quickly.

Although Mei experienced a delay in receiving professional support, it was not caused by the family's reluctance to seek help. Like Keung's family, Mei's husband did 'invite' outside help early when he recognized her deteriorating mental health. Their different helpseeking experiences could be explained by the ability of their respective General Practitioners (GPs) to detect symptoms of mental illness. Platz et al.'s (2006) study confirmed the pivotal role of GPs in early identification of mental illness so that timely specialist services could be 
offered. Williams et al. (2006) voiced their concern that because many medical professionals adopted Eurocentric conceptual frameworks to understand experiences of people from minority ethnic communities in Britain, they were unable to detect symptoms of mental distress. A study on the help-seeking behaviours of Chinese Americans raised similar concern (Kung, 2003).

The size of social networks became bigger and its composition became more diverse after first contact with mental health services. Mei and Keung were in active employment in the catering trade before they became mentally unwell. Because of mental illness, they had to resign from their jobs.

'She couldn't peel the potato; she couldn't take the orders from the customers'. (Mei's Husband)

'After my first relapse, I found a job in a restaurant run by white people. They didn’t discriminate against me ...... People from the Chinese community would discriminate, so I didn't want to work for the Chinese. When I had another relapse, I had to resign from the job and I was unable to work again'. (Keung)

Loss of job changed the composition of their social networks and their networks were no longer limited to close relatives and people working in the catering industry. Both Mei and Wah did voluntary work for their local Chinese community centre. They were also introduced to the Chinese community workers and different mental health professionals for support. This meant that they could access a bigger and a more diverse pool of resources for support and advice. 


\section{Geographical distribution}

Participants expressed difficulty in enlisting support from their social networks when they first became unwell as many of them did not live nearby. For example, Keung's family lived 70 miles away when he first became mentally unwell. When Mei's mental health deteriorated, her husband found it difficult to get support from other relatives as they did not live close to them.

'Help? My relatives were very busy with their businesses, they lived far away, how could they help?....I felt so desperate...' (Mei's husband)

Our findings revealed that the employment history could have huge implications on the composition and geographical distribution of social networks of Chinese immigrants in the UK. Chinese immigrants who work in the catering industry are a fluid community. They tend to travel between cities before they settle down in a place where they can earn a good living. For example, Mei lived in three different cities in the first 5 years since she came to the UK.

I always knew that the Chinese population is very dispersed in this country. However, I didn't realize that it was such a mobile community and how it could affect the structure of their social networks (extract from reflective diary).

Because they move around frequently, it is difficult for them to establish and sustain social relationships. Therefore, their network size is small and social connections are mainly confined to those working in the catering trade. Due to the disabling impact of mental illness, sufferers of SMI were forced out of employment and therefore did not need to travel between different cities to look for work. They either stayed in the same city or moved to another city where they had social affiliations. Ironically, this enabled them to develop and maintain social 
relationships. Consequently, their network size expanded and the network composition became more diverse; research participants were able to access a larger social network and wider range of social connections to meet their diverse needs.

'After I became unwell, we moved to live in the same city as my brother-in-law, he took me to see the doctor and interpret for me whenever he could..... there was also my friend, she helped me interpret over the phone..... I would go to see the Chinese community worker when I needed her support.' (Mei)

\section{Function of Social Networks and its relationship with help-seeking}

\section{Instrumental support}

Before first contact with mental health services, practical support was mainly provided by immediate family. They accompanied relatives suffering from SMI to attend medical appointments. For example, Keung's parents brought him home and took him to see the GP. Mei's husband took Mei to see the doctor; however, language differences presented a major barrier for Mei and her husband during medical consultations. The unavailability of social connections who could act as interpreters to articulate the husband's concern caused delay in getting specialist support. Mei also explained how she struggled to communicate with the psychiatrist:

'I told my psychiatrist that he couldn't cure me. He didn't allow me to go home. I pushed all the medication away. He said no, no..... I felt so miserable. I couldn't speak any English and he didn't understand me.' 
Many studies found that language difference could be a barrier for many Chinese to access mainstream services. Their lived experiences told me exactly what the difficulties were like (extract from reflective diary).

After their first contact with mental health services, because of the changes of the structural aspects of their social networks, all research participants were able to mobilize people from different networks to enlist practical support. For example, they would approach the Chinese support workers to interpret for them if no one from their informal networks was able to help.

\section{Advice / information}

Recognition of mental illness symptoms and knowledge of mental health services can facilitate early intervention. Poor recognition of mental illness symptoms seemed to be one of the main reasons for Wah's parents not seeking professional support from mental health specialists.

'His parents did not believe he had mental illness, they thought his behaviours were caused by a physical illness'. (Chinese community worker)

Wah's neighbour, who had a nursing background and recognized the signs of mental illness, took Wah to the hospital for professional support. Recognition of mental illness by Keung's colleagues prompted his family to take immediate action to seek professional support. Although Mei's husband initiated help-seeking at an early stage, the absence of social connections that could provide access information to mental health services caused a delay in getting professional treatment.

Since the first contact with formal mental health services, all research participants were provided with information about crisis and community mental health services. Chinese 
community workers provided welfare advice and other support services for all research participants and their families. Advice and information from the informal networks explained why Mei and Keung also sought help from folk healers.

'I have a friend in Hong Kong, he preformed ritual practice for me... it saved me, he saved me.' (Mei)

'We heard from a friend who was possessed by an evil spirit. Her family sought spiritual healing and the evil spirit left her..... We tried to visit the spiritual healer but it didn't work.' (Keung)

This confirms my understanding of British Chinese as many of them are prepared to travel great distance to seek help to treat health related problems (extract from reflexive diary).

Referring to figure 1, it showed that although sufferers of SMI continue to receive mental health services, they did not rigidly follow the treatment regime provided by the biomedical model. Mei and Keung used western medicine and lay and folk healing simultaneously to look after their mental health. The health belief held by their families plays a significant role in making health care decisions; Mei and Keung's family sought help from ritual practices through their social connections in Hong Kong and England respectively. It was found that Chinese people suffering from SMI in Singapore (Chong et al., 2005) and Malaysia (Gill et al., 2005) also consulted religious healers for advice. Keung also used traditional Chinese medicine prepared by his wife to counteract the unpleasant side effect of the western medicine. Such a pragmatic approach of medical pluralism appears to be very common among British Chinese (Chau and Yu, 2004) and overseas Chinese in America (Kung, 2001, 2003) and Australia (Hsiao et al., 2006). 


\section{Emotional support}

Mental illness could be the cause for the poor relationship between Wah and his parents, which was one of the reasons that Wah moved out of the family home.

'My parents sold the house, I had nowhere to live, I became homeless'. (Wah)

Family breakdown aggravated Wah's mental health. After leaving the family home, Wah was left with no choice but to live in temporary accommodation. This made it difficult for him to develop and maintain the social relationships which might have helped him obtain professional support early.

Mental illness could have a negative impact on family relationship. The theme of 'abandonment' emerged in all three cases but it manifested very differently across cases. According to Wah, his relationship with his parents reached a breaking point when they sold the family home. Since Wah was discharged from the mental health hospital, their relationship has improved and the family has regular contacts and has dinner together on a weekly basis. However, Wah refused to have his parents involved in the planning of his mental health care. He sought emotional support from the Chinese community worker and asked her to accompany him to see the psychiatrist. The community worker explained:

'He could speak fluent English but he wanted me there to provide him some moral and emotional support.'

In relation to the impact of mental illness on spousal relationship, after repeated relapses, Mei’s husband left her for a number of years. Mei said, 
'When I was in the hospital .... he told me he was going back to Hong Kong. He found another woman. He didn't want me. .. he didn't want his wife. Even if he wants me now, I am no good, I am crazy, I am a waste of space, I am useless. '

Although Mei's husband returned to the UK eventually and they met for lunch almost every day, they were no longer living as husband and wife. Mei had to turn to other people in her networks for practical support when she visited her doctors.

Whilst for Keung, despite repeated relapses, his wife stood by him for almost 17 years. She was willing and preferred to look after him at home. When Keung experienced relapses, inpatient hospital treatment was often the last resort. She always accompanied Keung to the hospital and all admissions were informal admissions. Also, because of this supportive relationship, Keung's wife was the person to decide whom and when to approach for help. She explained:

'My friend asked me why I didn't give up on him, leave him. I just couldn't. It was not his fault that he became unwell. I just couldn't leave him.'

Our findings demonstrate that Chinese people suffering from SMI do not experience a network crisis as postulated by Holmes-Eber and Riger (1990). Although all participants had a relatively long mental health history and repeated relapses could have a negative impact on family relationships, it did not necessarily lead to total abandonment or rejection of relatives with mental illness as suggested by Lin and Lin (1981). Persons suffering from SMI in this study still maintained close and regular contacts with their relatives. Moreover, similar to Brea's study (2008), our findings showed that when people suffering from SMI failed to get the support they needed from their intimate relationships, they would develop different 
strategies to reshape their social networks. For example, although Mei maintained regular contact with her husband after his return, she realized that she could not rely on him to look after her mental health needs. Hence, she reconstructed her social networks by establishing new social relationships so that she could turn to them for help when she needed to.

\section{Limitations of the study}

The present study has some limitations which should be taking into considerations when interpreting the results. It was an exploratory phase of a larger study and therefore the sample size is relatively small, thus the findings may not be transferrable to other settings. In the main study, we aim to recruit a bigger and heterogeneous sample to reflect the diversity of the Chinese community. Secondly, as is the potential for any qualitative study, sample bias might exist as only those who were willing to take part in the study were interviewed and therefore we cannot be sure that they represent all Chinese people with SMI. Finally, this was a retrospective study and there is a danger that recall bias may have occurred.

\section{Conclusions and Implications for Social Work Practice}

Our findings suggest that poor recognition of symptoms of mental illness (Wah's parents) and the lack of knowledge of mental health services (Mei's husband) of family of persons suffering from SMI were some of the reasons for delay in obtaining professional support. As social networks play a significant role in the help-seeking process, knowledge and information that promote early recognition and management of mental illness should be disseminated at the community level. This is to increase the likelihood that people with mental health needs can be assisted to get help through their social connections. 
The results of this study reveal that family may not be involved in every stage of helpseeking. Social workers and mental health professionals need to play a proactive role to identify local Chinese community resources which could meet the language and cultural needs of this marginalized group. Further research is required to explore innovative methods to deliver culturally competent mental health services for this dispersed community.

Our findings also serve to inform practitioners and policy makers that mainstream mental health services may not be the only or the preferred route to mental health care among Chinese immigrants. Further study of the use of alternative healers is needed to investigate how they can be usefully incorporated into mainstream mental health services in order to aid early diagnosis and manage mental illness. We also need to examine if the adoption of a mixed approach to look after people's mental health will cause any undesirable side effects. This is to ensure that proper advice can be given if people choose to take both Western and Chinese medicine simultaneously.

Help-seeking is a complex social activity. The study illuminates the dynamic relationship between changes of network structure and help-seeking experiences during the course of mental illness of Chinese immigrants suffering from SMI in England. Their unique help-seeking experience is clearly different from people living in other Chinese societies. The fluidity of the family boundary provides a window of opportunity for the 'outside world' to offer appropriate support and advice. The next stage of our main study will further examine the experiences of those who are involved in help-seeking so that factors that facilitate and hinder help-seeking can be identified. Suggestions can then be made to target policy and practice reforms and to develop services more relevant to the needs of British Chinese. The 
results will extend our understanding of help-seeking journeys amongst overseas Chinese; it can have significant implications for Chinese people living in different parts of the world. Furthermore, the findings will be relevant to other minority ethnic groups in the UK.

\section{Acknowledgement}

We would like to thank the research participants for taking part in this study. We are also grateful for the comment from the reviewers. Thanks are also extended to Wai Yin Chinese Women Society who partly funded this study. 


\section{References}

Albert, M., Becker, T., McCrone, P. and Thornicroft, G. (1998) 'Social networks and mental health service utilisation- a literature review', International Journal of Social Psychiatry, 44(4), pp. 248-266.

Aspinall, P. (2007) 'Language ability: a neglected dimension in the profiling of populations and health service users', Health Education Journal, 66(1), pp. 90-106.

Brea, P. (2008) The ripple effect: social network dynamics, social location, and strategies of interaction in mental illness careers, Indiana University.

Care Quality Commission (2010) Count me in 2009: results of the 2009 national census of inpatients and patients on supervised community treatment in mental health and learning disability services in England and Wales, London, Care Quality Commission.

Chan, C.K., Cole, B. and Bowpitt, G. (2007) "Beyond silent organizations': A reflection of the UK Chinese people and their community organizations', Critical Social Policy, 27(4), pp. 509-533.

Chau, C.M.R. and Yu, S. (2004) 'Pragmatism, globalism and culturalism: health pluralism of Chinese people in Britain', in Shaw, I. and Kauppinen, K. (eds), Constructions of health and illness: European perspectives, Aldershot, Ashgate.

Chong, S.A., Lum, M.A., Chan, Y.H. and McGorry, P.D. (2005) 'Determinants of duration of untreated psychosis and the pathway in Singapore', International Journal of Social Psychiatry, 51(1), pp. 55-62. Chiu, S. and Yu, S. (2001) 'An excess of culture: the myth of shared care in the Chinese community in Britain', Ageing and Society, 21(6), pp. 681-699.

Craddock, N., O'Donovan, M.C. and Owen, M.J. (2005) 'The genetics of schizophrenia and bipolar disorder: dissecting psychosis', Journal of Medical Genetics, 42(3), pp. 193-204.

Dowling, M. (2007) 'From Husserl to van Manen. A review of different phenomenological approaches', International Journal of Nursing Studies, 44(1), pp. 131-142. 
Gill, J.S., Koh, O.H. and Jambunathan, S.T. (2005) 'First-episode psychosis in a Malaysian Chinese population', Hong Kong Journal of Psychiatry, 15(2), pp. 54-59.

Heidegger, M. (1962) Being and time, Oxford, Blackwell Publishing.

Holmes-Eber, P. and Riger, S. (1990) 'Hospitalization and the composition of mental patients' social networks', Schizophrenia Bulletin, 16(1), pp. 157-164.

Horwitz, A. (1978) 'Family, kin, and friend networks in psychiatric help-seeking', Social Science \& Medicine. Part A: Medical Psychology \& Medical Sociology, 12, pp. 297-304.

Hsiao, F.H., Klimidis, S., Minas, H.I. and Tan, E.S. (2006) 'Folk concepts of mental disorders among Chinese-Australian patients and their caregivers', Journal of Advanced Nursing, 55(1), pp. 58-67. Husserl, E. (1983) Ideas pertaining to a pure phenomenology and to a phenomenological philosophy, The Hague, Martinus Nijhoff Publishers.

Irvine, F., Roberts, G. and Bradbury-Jones, C. (2008) 'The researcher as insider versus the researcher as outsider: enhancing rigour through language and cultural sensitivity', in Liamputtong, P. (ed), Doing Cross-cultural research: ethical and methodological perspectives, Springer.

Kirke, D.M. (2009) 'Social network analysis', in Gray, M. and Webb, S.A. (eds), Social work: theories and methods, London, Sage Publications.

Klimidis, S., Hsiao, F.H. and Minas, H.I. (2007) 'Chinese-Australians' knowledge of depression and schizophrenia in the context of their under-Utilization of mental health care: an analysis of labelling ', International Journal of Social Psychiatry, 53(5), pp. 464-479.

Knoke, D. and Yang, S. (2008) Quantitative Applications in the Social Sciences, Thousand Oaks, Sage Publications.

Kung, W. (2001) 'Consideration of cultural factors in working with Chinese American families with a mentally ill patient', Families in Society, 82(1), pp. 97-107. 
Kung, W. (2003) 'Chinese Americans' help seeking for emotional distress', Social Service Review, 77, pp. 110-134.

Lee, S., Lee, M., Chiu, M. and Kleinman, A. (2005) 'The experience of social stigma by patients with schizophrenia in Hong Kong ', British Journal of Psychiatry, 186(2), pp. 153-157.

Li, P. L. and Logan, S. (1999) The mental health needs of Chinese people in England: a report of a national survey, London, Chinese National Healthy Living Centre.

Lin, T.Y. and Lin, M.C. (1981) 'Love, denial and rejection: responses of Chinese families to mental illness', in Kleinman, A. and Lin, T.Y. (eds), Normal and abnormal behavior in the Chinese culture, Dordrecht, D. Reidel Publishing Company.

Moustakas, C. (1994) Phenomenological research methods, Thousand Oaks, Sage Publication.

Office for National Statistics (2002) Census 2001: first result on population for England and Wales, HMSO. Olson, D.H. and Grorall, D.M. (2003) 'Circumplex Model of marital and family systems', in Walsh, F. (ed), Normal family process, New York, Guilford.

Pescosolido, B.A. and Wright, E.R. (2004) 'The view from two worlds: the convergence of social network reports between mental health clients and their ties', Social Science \& Medicine, 58(9), pp. 1795-1806. Phillips, M. R., Li, Y., Stroup, T. S. and Xin, L. (2000) 'Causes of schizophrenia reported by patients' family members in China', The British Journal of Psychiatry, 177(1), pp. 20-25.

Platz, C., Umbricht, D., Cattapan-Ludewig, K., Dvorsky, D., Arbach, D., Brenner, H. and Simon, A. (2006) 'Help-seeking pathways in early psychosis', Social Psychiatry and Psychiatric Epidemiology, 41(12), pp. 967-974.

Polkinghorne, D. (1983) Methodology for the human sciences: system of inquiry, State University of New York, Albany.

Ryder, A.G., Bean, G. and Dion, K.L. (2000) 'Caregiver responses to symptoms of first-onset psychosis: a comparison study of Chinese and Euro-Canadian families', Transcultural Psychiatry, 37(2), pp. 225-235. 
The Information Centre (2006) 'Health survey for England: the health of minority ethnic groups: summary of findings', The Information Centre.

Wall, C., Glen, S., Mitchinson, S. and Poole, H. (2004) 'Using a reflective diary to develop bracketing skills during a phenomenological investigation', Nurse Researcher, 11(4), pp. 20-29.

Williams, P.E., Turpin, G. and Hardy, G. (2006) 'Clinical psychology service provision and ethnic diversity within the UK: a review of the literature', Clinical Psychology and Psychotherapy, 13(5), pp. 324-338. Wong, D.F.K. (2007) 'Crucial individuals in the help-seeking pathway of Chinese caregivers of relatives with early psychosis in Hong Kong', Social Work, 52(2), pp. 127-135. 